\title{
Associations of Food Addiction in a Sample Recruited to be Nationally Representative of the
} $\underline{\text { United States }}$

Erica M. Schulte and Ashley N. Gearhardt

\author{
Author Note \\ Erica M. Schulte and Ashley N. Gearhardt are affiliated with the Department of \\ Psychology at University of Michigan. \\ Correspondence concerning this article should be addressed to Erica M. Schulte, \\ Department of Psychology, University of Michigan, 2257 East Hall, 530 Church Street, Ann \\ Arbor, MI 48109. Phone: (913) 653-5022. Email: eorenste@umich.edu.
}

This is the author manuscript accepted for publication and has undergone full peer review but has not been through the copyediting, typesetting, pagination and proofreading process, which may lead to differences between this version and the Version of Record. Please cite this article as doi: $10.1002 /$ erv.2575

This article is protected by copyright. All rights reserved. 
FOOD ADDICTION IN THE UNITED STATES

\begin{abstract}
The current study investigated the prevalence of food addiction and its associations with obesity and demographic factors in a sample recruited to be more nationally representative of the United States than previous research. Individuals $(n=1050)$ were recruited through Qualtrics' qBus, which sets demographic quotas developed using the United States census reference population. Participants ( $n=986)$ self-reported food addiction, measured by the modified Yale Food Addiction Scale 2.0 (mYFAS 2.0), height, weight, age, gender, race, and income. Food addiction was observed in $15 \%$ of participants, with greater prevalence in individuals who were younger, Hispanic, and/or reported higher annual income. Food addiction prevalence was higher in persons who were underweight or obese, relative to normal weight or overweight. Food addiction was associated with higher BMI in women and persons who were older, White, and/or reported lower income. Identifying the scope of food addiction and individual risk groups may inform public policy initiatives and early intervention efforts.
\end{abstract}

This article is protected by copyright. All rights reserved. 
FOOD ADDICTION IN THE UNITED STATES

\section{Introduction}

Food addiction reflects the theory that some individuals may experience an addictive-like response to foods high in fat and/or refined carbohydrates like sugar, akin to a substance-use disorder (Ahmed, Avena, Berridge, Gearhardt, \& Guillem, 2013; Davis et al., 2011; Gearhardt, Davis, Kuschner, \& Brownell, 2011). In support, studies in animals and humans have demonstrated biobehavioral indicators of addiction in response to foods high in fat and/or refined carbohydrates (Avena, Rada, \& Hoebel, 2008; Gearhardt, Yokum, et al., 2011; Johnson \& Kenny, 2010; Oswald, Murdaugh, King, \& Boggiano, 2011; M. J. Robinson et al., 2015). However, the theory remains controversial, particularly because research aiming to identify the addictive agent in food (e.g., added sugar) is in its nascent stages (Ziauddeen \& Fletcher, 2013) and the unique clinical utility of the construct is debated (Davis, 2013; D. G. Smith \& Robbins, 2013). There also exist alternative perspectives suggesting that food addiction is better conceptualized and measured as a behavioral addiction to the act of eating (Hebebrand et al., 2014; Ruddock, Christiansen, Halford, \& Hardman, 2017).

While there is no agreed upon definition of food addiction, the phenotype is most frequently measured in humans by the Yale Food Addiction Scale (YFAS). Importantly, as food addiction is not a clinical diagnosis recognized by the Diagnostic and Statistical Manual (DSM) (American Psychiatric Association, 2013), the term 'food addiction' in the current manuscript will henceforth reflect the classification made by the YFAS. The YFAS is a self-report measure that adapts the DSM criteria for substance-use disorders to evaluate addictive-like consumption 
FOOD ADDICTION IN THE UNITED STATES

of foods high in fat and/or refined carbohydrates (Gearhardt, Corbin, \& Brownell, 2009, 2016). The YFAS has been associated with clinically relevant features, such as frequency of binge eating episodes, weight cycling, obesity, and short-term abstinence from binging-purging in persons with bulimia nervosa following intervention (Davis et al., 2011; Gearhardt, Boswell, \& White, 2014; Granero et al., 2014; Hilker et al., 2016; Schulte \& Gearhardt, 2017). However, many previous studies of food addiction have consisted of small samples or samples with limited generalizability to the national population (e.g., clinical samples, undergraduates, overrepresentation of females and White individuals). These limitations present a challenge in estimating the scope of food addiction and its relation to individual characteristics (e.g., gender, race) (Pursey, Stanwell, Gearhardt, Collins, \& Burrows, 2014).

In convenience and general population samples, the reported prevalence of food addiction has ranged from approximately 5\% to 57\%, with a weighted mean estimate of $19.9 \%$ (Pursey et al., 2014). Only one study, in a German sample, has employed online, quota-based techniques to recruit a more nationally representative sample and observed a food addiction prevalence of 7.9\% (Hauck, Weiss, Schulte, Meule, \& Ellrott, 2017). This approach warrants replication in the United States, where rates of obesity are notably higher than Germany (Mensink et al., 2013; Ogden, Carroll, Kit, \& Flegal, 2014). Thus, assessment of food addiction in a more nationally representative sample may allow for a more accurate point prevalence estimation in the United States and allow for comparison of prevalence between countries. 
FOOD ADDICTION IN THE UNITED STATES

Previous studies have also examined which groups of individuals may have elevated food addiction prevalence. YFAS food addiction appears to be more prevalent in females (Gearhardt et al., 2016; Hauck et al., 2017; Pedram et al., 2013; Pursey et al., 2014) and younger individuals (Flint et al., 2014; Hauck et al., 2017; Schulte \& Gearhardt, 2017). Findings regarding the association of YFAS food addiction with racial identification have been mixed (Pursey et al., 2014), with studies observing higher prevalence of food addiction in individuals identifying as White (Flint et al., 2014), Hispanic (Schulte \& Gearhardt, 2017), and African-American (Eichen, Lent, Goldbacher, \& Foster, 2013). Further, income appears to be associated with eating-related problems and obesity (Singh, Kogan, Van Dyck, \& Siahpush, 2008; Sobal \& Stunkard, 1989; Wardle, Waller, \& Jarvis, 2002) but has not been investigated fully with respect to food addiction.

In addition, an important health outcome associated with YFAS food addiction is obesity (Flint et al., 2014; Hauck et al., 2017; Meule \& Gearhardt, 2014; Pedram et al., 2013; Pursey et al., 2014). Given the neurobiological and behavioral similarities observed between obesity and substance-use disorders, it has been suggested that food addiction may be a clinically meaningful phenotype within obesity (Davis et al., 2011; D. G. Smith \& Robbins, 2013; Volkow \& Wise, 2005). While there appears to be a link between YFAS food addiction and increased body mass index (BMI) in previous studies using convenience or general population samples (Pursey et al., 2014), the majority of existing studies investigated samples overrepresented with women, individuals who are White, and limited age ranges (Pursey et al., 2014). Thus, replication is 
FOOD ADDICTION IN THE UNITED STATES

needed in a sample more representative for age, gender, and race. Further, a more representative sample may highlight groups of individuals where addictive-like eating may be most significantly associated with obesity.

Thus, using a sample more representative of the United States population than prior research, the current study has three aims. First, the prevalence of food addiction and its associations with individual characteristics (age, gender, race, income) will be assessed. Second, the association between food addiction with BMI and weight class (underweight, normal weight, overweight, obese) will be investigated. Third, the present approach will explore whether the association between food addiction and BMI differs based on individual characteristics (age, gender, race, income). Examining which persons have the highest prevalence of food addiction and strongest association of food addiction with obesity may aid in identifying populations that may benefit most from intervention approaches that address features of addiction (e.g., craving management) or public policy initiatives (e.g., restricting marketing to vulnerable groups). 
FOOD ADDICTION IN THE UNITED STATES

\section{Materials and Methods}

The University of Michigan Health and Behavioral Sciences Institutional Review Board approved the current study (HUM00117661) as exempt from ongoing review.

\section{Participants}

Participants were recruited through Qualtrics' qBus, an omnibus survey sent out to 1050 individuals. Individuals were compensated by Qualtrics with points that can be redeemed for incentives (e.g., gift cards). Quotas are set based on the United States Census data for gender, race, household income, and geographic region, and the survey remains open until quota groups are filled.

Analyses were conducted with 986 individuals, after excluding 48 respondents who had nonsensical data (e.g., reporting age as "1234") and 16 for reporting BMI $<10$ or $>75$. A wider range of BMI was permitted in the present study to allow for representation across weight classes, and the present sample paralleled the frequency of "extreme obesity" (BMI>40) in other nationally representative samples (current sample frequency: 6.4\%; frequency in National Health and Nutrition Examination Survey (NHANES) dataset: 6.3\% (Fryar, Carroll, \& Ogden, 2012)). Gender, race, and income were similar to the 2010 United States census reference population (www.census.gov) (see Table 1). Participants were 51.2\% female, with an average age of 44.91 $(S D=16.27)$. Self-reported racial identification was $68.4 \%$ White, $12.7 \%$ African American, 12.6\% Hispanic, 3.2\% Asian, and 3.1\% Other. Average self-reported BMI was 27.53 (SD=7.38), with the following weight class categorizations: $4.7 \%$ underweight $(\mathrm{BMI}<18.5), 37.5 \%$ normal

This article is protected by copyright. All rights reserved. 
FOOD ADDICTION IN THE UNITED STATES

weight $(\mathrm{BMI}=18.5-24.9), 30.4 \%$ overweight $(\mathrm{BMI}=25.0-29.9)$, and 27.4\% obese $(\mathrm{BMI}>30)$.

Participants' median income was $\$ 50,000-\$ 74,999$.

\section{Measures}

\section{Modified Yale Food Addiction Scale 2.0 (mYFAS 2.0)}

The abbreviated form of the current version of the YFAS, the mYFAS 2.0 (Schulte \& Gearhardt, 2017) was used to measure the eleven indicators of and threshold for food addiction in the current sample. The psychometric performance and scoring methods of the mYFAS 2.0 is detailed in the validation paper (Schulte \& Gearhardt, 2017). In the current study, the mYFAS 2.0 exhibited excellent reliability $(\alpha=.97)$.

$\underline{\text { BMI and Demographics }}$

BMI was calculated using self-reported height and weight. Further, participants selfreported several demographic variables: age, gender (male, female), racial identification (White/Caucasian, Black/African American, Hispanic/Latino, Asian, Other), and annual household income.

\section{Data Analytic Plan}

All study variables were first examined for outliers and skewness $(<2)$. Consistent with the three study aims, correlations, analysis of variance (ANOVA) tests, t-tests, and chi-square tests were first utilized to examine the relationship between mYFAS 2.0 scores and demographic variables (age, gender, race, income). Effect sizes $\left(\eta_{\mathrm{p}}{ }^{2}\right)$ were calculated and reported to indicate the magnitude of the finding in a manner that is independent from sample size. Effects can be 
FOOD ADDICTION IN THE UNITED STATES

considered small at $\eta_{\mathrm{p}}{ }^{2}=.01-.06$, medium at $\eta_{\mathrm{p}}{ }^{2}=.06-.14$, and large at $\eta_{\mathrm{p}}{ }^{2}>.14$ (Richardson, 2011)

$\eta_{\mathrm{p}}^{2}$. Tukey's HSD tests were used to follow up significant ANOVA omnibus tests. Second, univariate general linear modeling (GLM) investigated the associations of mYFAS 2.0 with 1) BMI and 2) weight class (underweight, normal weight, overweight, and obese). Third, multivariate GLM was used to explore the main effects and interactions of mYFAS 2.0 and the four individual characterstics (age, gender, race, income) on BMI. Given that all main effects and interactions were significant in this multivariate model, separate models assessing the main effects and interactions of each demographic variable with mYFAS 2.0 are presented for ease of interpretation. As prior literature has observed opposite associations between age with YFAS and BMI (Flint et al., 2014; Hauck et al., 2017), all analyses examining the association of mYFAS 2.0 scores with BMI included age as a covariate. 
FOOD ADDICTION IN THE UNITED STATES

\section{Results}

mYFAS 2.0

The average number of food addiction symptoms endorsed on the mYFAS 2.0 was 1.81 $(S D=3.18)$ and ranged from 0 to 11 . Further, $15.0 \%$ of participants met the diagnostic threshold score for mYFAS 2.0 food addiction ( $1.0 \%$ mild, $2.4 \%$ moderate, $11.6 \%$ severe). Table 2 details the average mYFAS 2.0 symptoms and prevalence for all demographic characteristics. mYFAS 2.0 with Demographics

Age was significantly negatively associated with the mYFAS 2.0 symptom $(r=-.28$, $\mathrm{p}<0.001)$ and diagnostic scores $\left(\mathrm{t}(984)=48.66, \mathrm{p}<0.001, \eta_{\mathrm{p}}{ }^{2}=.05\right)$, with individuals meeting the diagnostic threshold being younger $(\mathrm{M}=36.51, S D=11.39)$ than those who did not $(\mathrm{M}=46.39$, $S D=16.55)$. mYFAS 2.0 symptom and diagnostic scores did not significantly differ by gender (ps>0.21). Self-reported racial identification (White, African-American, Hispanic, Asian, other) was significantly associated with the mYFAS 2.0 symptom count score $(\mathrm{F}(4,981)=18.27$, $\mathrm{p}<0.001, \eta_{\mathrm{p}}{ }^{2}=.07$ ), with individuals who identified as Hispanic endorsing more mYFAS 2.0 symptoms than those who reported being White, African American, or other race $(\mathrm{ps}<0.01)$. These findings were replicated using the mYFAS 2.0 diagnostic score. The mYFAS 2.0 symptom count score was positively correlated with income $(\mathrm{r}=.10, \mathrm{p}=0.001)$, as was the mYFAS 2.0 diagnostic score $(\mathrm{p}<0.05)$. Table 3 (in supplementary materials) provides the correlations between all continuous study variables.

mYFAS 2.0, BMI, and Weight Class

This article is protected by copyright. All rights reserved. 
FOOD ADDICTION IN THE UNITED STATES

mYFAS 2.0 symptom count became significantly related to BMI $(F(11,973)=6.22$, $\left.\mathrm{p}<0.001, \eta_{\mathrm{p}}{ }^{2}=.07\right)$ when age was included as a covariate. The mYFAS 2.0 diagnostic score was also associated with BMI $\left(\mathrm{F}(1,983)=11.34, \mathrm{p}=0.001, \eta_{\mathrm{p}}{ }^{2}=.01\right)$. The relationship between mYFAS 2.0 and BMI only becoming significant when including age as a covariate seems to reflect a steeper drop-off in obesity prevalence, relative to food addiction prevalence, after age 44 (see Figure 1).

Weight class categorization (underweight, normal weight, overweight, obese) was significantly associated with the mYFAS 2.0 symptom count score $(F(3,981)=18.05, \mathrm{p}<0.001$, $\left.\eta_{\mathrm{p}}{ }^{2}=.05\right)$. Post-hoc analyses revealed a quadratic relationship, such that underweight individuals endorsed more mYFAS 2.0 symptoms than all other weight classes (ps<0.001), and obese individuals reported significantly greater mYFAS 2.0 symptoms than normal weight $(\mathrm{p}=0.006)$ and overweight persons $(\mathrm{p}=0.001)$. This pattern of results was also observed for the mYFAS 2.0 diagnostic score. Figure 2 models the prevalence of the mYFAS 2.0 diagnostic score across weight classes.

mYFAS 2.0, BMI, and Demographics

Age, mYFAS 2.0, and BMI

There were significant main effects for mYFAS 2.0 symptom count $(F(11,962)=3.12$, $\left.\mathrm{p}<0.001, \eta_{\mathrm{p}}{ }^{2}=.03\right)$ and age $\left(\mathrm{F}(1,962)=29.17, \mathrm{p}<0.001, \eta_{\mathrm{p}}{ }^{2}=.03\right)$ on BMI. There was also a significant interaction between mYFAS 2.0 symptom count and age $(\mathrm{F}(11,962)=4.31, \mathrm{p}<0.001$, $\left.\eta_{\mathrm{p}}{ }^{2}=.05\right)$, where elevated symptom count was associated with higher BMI in older individuals 
FOOD ADDICTION IN THE UNITED STATES

(those above the sample mean of 44.91) $(\mathrm{r}=.32, \mathrm{p}<0.001)$ but not younger individuals (those below the sample mean of 44.91) $(\mathrm{p}=.25)$. This pattern of results was replicated with the mYFAS 2.0 diagnostic score.

Gender, mYFAS 2.0, and BMI

mYFAS 2.0 symptom count $\left(\mathrm{F}(11,961)=6.07, \mathrm{p}<0.001, \eta_{\mathrm{p}}{ }^{2}=.07\right)$ and gender $\left(\mathrm{F}(1,961)=8.93, \mathrm{p}=0.003, \eta_{\mathrm{p}}{ }^{2}=.01\right)$ were significantly related to BMI. There was a significant interaction between mYFAS 2.0 symptom count and gender $\left(F(11,961)=3.77, \mathrm{p}<0.001, \eta_{\mathrm{p}}{ }^{2}=.04\right)$, where elevated symptom count was associated with higher BMI in women $(r=.20, p<0.001)$ but not men ( $\mathrm{p}=.07)$ (see Figure 3 in supplementary materials). These findings were also observed for the mYFAS 2.0 diagnostic score.

$\underline{\text { Race, mYFAS 2.0, and BMI }}$

There was a significant main effect of racial identification $(\mathrm{F}(4,933)=4.90, \mathrm{p}=0.001$, $\left.\eta_{\mathrm{p}}{ }^{2}=.02\right)$ but not mYFAS 2.0 symptom score $(\mathrm{p}=.51)$ on BMI. There was a significant interaction between mYFAS 2.0 symptom score and racial identification $(F(36,933)=1.75, \mathrm{p}=0.004$, $\eta_{\mathrm{p}}{ }^{2}=.06$ ), with elevated mYFAS 2.0 symptom score being associated with higher BMI among those who identified as White $(\mathrm{r}=.12, \mathrm{p}=.002)$. However, for persons who identified as Hispanic, elevated mYFAS 2.0 symptom score was associated with lower BMI at trend-level significance $(\mathrm{r}=-.17, \mathrm{p}=.06)$, and for those who reported being African American, Asian, or other race, no significant relationship between mYFAS 2.0 symptom score and BMI was found (ps>.20) (see 
FOOD ADDICTION IN THE UNITED STATES

Figure 4 in supplementary materials). These findings were replicated using the mYFAS 2.0 diagnostic score.

Income, mYFAS 2.0, and BMI

Significant main effects were observed for mYFAS 2.0 symptom count $(\mathrm{F}(11,928)=5.44$, $\left.\mathrm{p}<0.001, \eta_{\mathrm{p}}{ }^{2}=.06\right)$ and income $\left(\mathrm{F}(4,928)=10.37, \mathrm{p}<0.001, \eta_{\mathrm{p}}{ }^{2}=.04\right)$ on BMI. There was a significant interaction for mYFAS 2.0 symptom score and income $(\mathrm{F}(41,928)=2.61, \mathrm{p}<0.001$, $\eta_{\mathrm{p}}{ }^{2}=.10$ ) with greater mYFAS 2.0 symptom scores being related to increased BMI only for those who reported an annual household income $<\$ 25,000(\mathrm{r}=.38, \mathrm{p}<0.001)$ and $\$ 25,000-\$ 49,999$ $(\mathrm{r}=.13, \mathrm{p}=.05)$ (see Figure 5 in supplementary materials). No significant relationship between mYFAS 2.0 symptom score and BMI was found for those who reported an annual household income between $\$ 50,000-\$ 74,999, \$ 75,000-\$ 99,999$, or $>\$ 100,000$ (ps>.14). These findings were replicated using the mYFAS 2.0 diagnostic score. 
FOOD ADDICTION IN THE UNITED STATES

\section{Discussion}

Prevalence of Food Addiction

In a sample more representative of the United States than previous research, $15.0 \%$ of individuals met the mYFAS 2.0 criteria for food addiction. This point-prevalence estimate is similar to previous research in the United States assessing food addiction with the YFAS 2.0 or mYFAS 2.0 in online community samples (Gearhardt et al., 2016; Schulte \& Gearhardt, 2017). Notably, the observed prevalence is nearly double the $7.9 \%$ estimate in a more nationally representative German sample (Hauck et al., 2017), which may be related to significantly higher obesity rates (Mensink et al., 2013; Ogden et al., 2014) and density of highly processed foods (e.g., fast foods) (Jeffery, Baxter, McGuire, \& Linde, 2006; Maddock, 2004) in the United States Notably, the current prevalence estimate of food addiction in the United States appears to be comparable to substance-use disorders where the substance is legal (e.g., alcohol: 13.9\% (Grant et al., 2015), tobacco: 20.0\% (Chou et al., 2016).

\section{Association of Food Addiction with BMI and Weight Class}

Paralleling findings from the more nationally representative German sample (Hauck et al., 2017), individuals who were underweight or obese exhibited greater rates of food addiction than those who were normal weight or overweight. While elevated rates of addictive-like eating in the obese weight class supports theoretical perspectives that addictive-like eating may be a phenotype of obesity (Davis et al., 2011; Pedram et al., 2013), elevated symptoms and prevalence of food addiction in individuals who were underweight necessitates further 
FOOD ADDICTION IN THE UNITED STATES

examination. One possible explanation may be that the YFAS is susceptible to differences in interpretation. For example, self-reported endorsement of consuming highly processed foods in greater quantities than intended may vary based on a person's intention (e.g., intending to consume three slices of pizza versus none). For individuals who are underweight and report food addiction, other factors (e.g., dieting, caloric deprivation) may mimic the behavioral indicators of addiction (e.g., consuming more than intended may originate from violation of dietary rules, intense craving may result from homeostatic drive for food in starved state). Further, rates of food addiction have been found to be higher among individuals with anorexia nervosa binge/purge type relative to restrictive type (Granero et al., 2014). Thus, examination of whether underweight individuals with food addiction are engaging in objective or subjective overeating may be necessary. Akin to substance-use disorders, the food addiction theory posits that individuals objectively, compulsively overeat highly processed foods. The development of an interview-style assessment of food addiction may be useful for evaluating whether an individual is exhibiting the addictive-like overconsumption of highly processed foods that the YFAS aims to operationalize.

Age

In line with previous findings, food addiction was associated with younger age (Flint et al., 2014; Hauck et al., 2017; Schulte \& Gearhardt, 2017), paralleling developmental trends in both eating disorders (Woodside \& Garfinkel, 1992) and substance-use disorders (Kessler et al., 2005). The current cross-sectional findings suggest that food addiction rates seem to increase 
FOOD ADDICTION IN THE UNITED STATES

until ages 35-44 before declining rapidly after age 45 . This may reflect a cohort effect related to changes in the food environment in the past few decades (e.g., greater portion sizes and accessibility of highly processed foods) (Gearhardt, Grilo, DiLeone, Brownell, \& Potenza, 2011) or neurobiological changes in the dopaminergic system across the lifespan that may result in diminished reward responsiveness to addictive substances (Bannon et al., 1992; Dowling, Weiss, \& Condon, 2008; Giros, Jaber, Jones, Wightman, \& Caron, 1996). Additionally, given that food addiction prevalence appears to peak in developmental years associated with child bearing and child rearing, future research may investigate possible associations between addictive-like eating and familial influences (e.g., number of children, marital status). Further, longitudinal research is needed to evaluate the trajectory of food addiction prevalence across the lifespan.

Notably, the association between BMI and food addiction only became significant after controlling for age, as age was negatively related to food addiction and positively associated with BMI, demonstrating that age may be a key factor to assess when examining the association between food addiction and obesity. Further, food addiction was associated with higher BMI in older but not younger individuals. It may be that younger persons with addictive-like eating behavior have biological protective factors (e.g., higher metabolism) or behavioral strategies (e.g., dieting, restrained eating) that contribute to weight control. Longitudinal research is needed to examine the temporal nature of these relationships, such as whether there is a steeper weight gain trajectory for younger individuals with food addiction.

\section{Gender}


FOOD ADDICTION IN THE UNITED STATES

In contrast to previous studies (Gearhardt et al., 2016; Hauck et al., 2017; Pedram et al., 2013; Pursey et al., 2014), food addiction was not related to gender in the present work. However, the association between food addiction and BMI did differ by gender, with elevated food addiction symptoms being associated with higher BMI for women but not men. The positive relationship between addictive-like eating and obesity in women is consistent with previous research (Flint et al., 2014), although the lack of this association for men is surprising. Given that food addiction may particularly implicated in obesity for women, relative to men, screening for addictive-like eating in women with obesity may inform treatment needs and possibly improve outcomes like body weight.

Race

Akin to prior work using the mYFAS 2.0 (Schulte \& Gearhardt, 2017), Hispanic individuals reported higher rates of addictive-like eating behavior relative to those who identified as White or African American. Findings related to the prevalence of related eating pathology (e.g., binge eating) Hispanic individuals relative to other racial groups are mixed (Cachelin, Veisel, Barzegarnazari, \& Striegel-Moore, 2000; Fitzgibbon et al., 1998; T. N. Robinson et al., 1996; J. E. Smith \& Krejci, 1991), although depressive symptomology has been particularly related to binge eating for Hispanic individuals (Fitzgibbon et al., 1998). From an addiction perspective, use of a substance to cope with negative affect is characteristic of individuals with substance-use disorders (Cooper, 1994), and recent research suggests that eating to cope with emotional states is linked to food addiction (Joyner, Schulte, Wilt, \& Gearhardt, 2015). Thus, 
FOOD ADDICTION IN THE UNITED STATES

one extension of the current findings may be to elucidate mechanisms (e.g., emotion dysregulation) that may differentially contribute to addictive-like eating for various racial groups.

Further, there was a positive association between food addiction and BMI for White persons, whereas the reverse relationship was observed for Hispanic participants. This finding first suggests that addictive-like eating may be particularly associated with obesity among White individuals. As such, early identification and treatment of food addiction indicators in this group may impact outcomes like obesity. In contrast, although Hispanic persons reported the most elevated indicators of food addiction, addictive-like eating was associated with lower body weight in this group. This is somewhat consistent with prior work demonstrating more severe binge eating in Hispanic relative to White and African American individuals, but also greater engagement in fasting-excessive dieting and use of diuretics for weight control (Fitzgibbon et al., 1998; J. E. Smith \& Krejci, 1991). Future research may evaluate whether other disordered eating behaviors (e.g., compensatory behaviors) interact with food addiction and body weight among Hispanic persons.

Income

Elevated rates of food addiction among individuals with greater income parallels greater rates of substance-use disorders in adults of higher socioeconomic classes (Humensky, 2010; Wohlfarth \& van den Brink, 1998). Additionally, it may be that these persons are more sensitive in self-reporting eating-related problems, as prior work has also observed that individuals of 
FOOD ADDICTION IN THE UNITED STATES

higher socioeconomic status are more aware of American body ideals and more likely to perceive overweight (Paeratakul, White, Williamson, Ryan, \& Bray, 2002; Wardle et al., 2004). In contrast, self-reporting addictive-like eating behavior may be more challenging in lower socioeconomic groups, where consumption of highly processed foods may be more frequent due in part to these foods being easily accessible and affordable (Bowman, Gortmaker, Ebbeling, Pereira, \& Ludwig, 2004; Fernandez-Alvira et al., 2014; Konttinen, Sarlio-Lahteenkorva, Silventoinen, Mannisto, \& Haukkala, 2013) and overconsumption of these foods may be viewed as normative (Malika, Hayman, Miller, Lee, \& Lumeng, 2015). This may be comparable to the issues of self-reporting drinking behavior within a population where frequent alcohol consumption is normative or socially desirable (e.g., college students) (Baer \& Carney, 1993; Baer, Stacy, \& Larimer, 1991; Del Boca \& Darkes, 2003).

There was also a positive association between food addiction and BMI among individuals from the two lowest annual income groups, whereas no relationship was observed for higher income groups. The convenience and affordability of highly processed foods may motivate their selection among individuals in low-income communities (Inglis, Ball, \& Crawford, 2005; Konttinen et al., 2013), as well as possible limited access to minimally processed foods like fruits and vegetables (Ball, Timperio, \& Crawford, 2009), in a manner that may increase body weight. Thus, public policy initiatives that increase the availability and affordability of a wider variety of foods may be beneficial for lower income socioeconomic groups, such as subsidizing fruits, vegetables, and lean proteins. 
FOOD ADDICTION IN THE UNITED STATES

\section{Limitations}

While this study employed techniques to collect a sample more nationally representative of the United States than prior research, there were demographic differences. Age was restricted to older than 18 due to consent and the percentage of individuals with obesity was lower than prior research (Ogden et al., 2014). Further, the standardized demographic questions used by Qualtrics assessed race in a different way than the United States census. For the census, individuals report being either Hispanic or Non-Hispanic then separately select their racial identification, whereas in the current approach, participants simply selected the most appropriate racial identification from the five choices (White, African American, Hispanic, Asian, other). Further, all data was participants' self-report, which may be subject to greater bias, particularly with respect to height and weight. Additionally, Qualtrics limited the number of questions that could be included and certain variables that may contribute to the observed relationships (e.g., eating disorder symptomology, dietary restraint) were unable to be accounted for. Broadly, the associations described warrant replication to support that the present findings did not result from Type I or Type II errors. In particular, the sample size was large and most effect sizes ranged from small-to-moderate. It will be important for future research to investigate the clinical significance of these findings. In addition, while the current study permitted recruitment of individuals from all regions of the United States, an in-lab investigation of food addiction with diverse individual characteristics may strengthen the present findings. Lastly, the nature of all observations was cross-sectional, and longitudinal research is essential for investigating the 
FOOD ADDICTION IN THE UNITED STATES

temporal associations between the variables to better assess risk factors and intervention opportunities.

\section{Conclusions}

Overall, the present study elucidates the prevalence of food addiction and its relationship to weight class in the United States and identifies which groups of individuals may be at elevated risk for addictive-like eating and for whom food addiction may be most related to obesity. Identifying the scope of food addiction and the individuals at greatest risk may inform which public policy initiatives may be effective (e.g., zoning requirements for fast food restaurants in low-income communities) and motivate early identification of food addiction in certain groups (e.g., screening of addictive-like eating in younger persons). 
FOOD ADDICTION IN THE UNITED STATES

\section{References}

Ahmed, S. H., Avena, N. M., Berridge, K. C., Gearhardt, A. N., \& Guillem, K. (2013). Food addiction Neuroscience in the 21st Century (pp. 2833-2857): Springer.

American Psychiatric Association. (2013). Diagnostic and statistical manual of mental disorders. Arlington: American Psychiatric Publishing.

Avena, N. M., Rada, P., \& Hoebel, B. G. (2008). Evidence for sugar addiction: behavioral and neurochemical effects of intermittent, excessive sugar intake. Neurosci Biobehav Rev, 32(1), 20-39. doi: 10.1016/j.neubiorev.2007.04.019

Baer, J. S., \& Carney, M. M. (1993). Biases in the perceptions of the consequences of alcohol use among college students. J Stud Alcohol, 54(1), 54-60.

Baer, J. S., Stacy, A., \& Larimer, M. (1991). Biases in the perception of drinking norms among college students. J Stud Alcohol, 52(6), 580-586.

Ball, K., Timperio, A., \& Crawford, D. (2009). Neighbourhood socioeconomic inequalities in food access and affordability. Health Place, 15(2), 578-585. doi: 10.1016/j.healthplace.2008.09.010

Bannon, M. J., Poosch, M. S., Xia, Y., Goebel, D. J., Cassin, B., \& Kapatos, G. (1992). Dopamine transporter mRNA content in human substantia nigra decreases precipitously with age. Proc Natl Acad Sci U S A, 89(15), 7095-7099.

Bowman, S. A., Gortmaker, S. L., Ebbeling, C. B., Pereira, M. A., \& Ludwig, D. S. (2004). Effects of fast-food consumption on energy intake and diet quality among children in a national household survey. Pediatrics, 113(1 Pt 1), 112-118.

Cachelin, F. M., Veisel, C., Barzegarnazari, E., \& Striegel-Moore, R. H. (2000). Disordered eating, acculturation, and treatment-seeking in a community sample of Hispanic, Asian, Black, and White women. Psychology of Women Quarterly, 24(3), 244-253.

Chou, S. P., Goldstein, R. B., Smith, S. M., Huang, B., Ruan, W. J., Zhang, H., ... Grant, B. F. (2016). The Epidemiology of DSM-5 Nicotine Use Disorder: Results From the National Epidemiologic Survey on Alcohol and Related Conditions-III. J Clin Psychiatry, 77(10), 1404-1412. doi: 10.4088/JCP.15m10114

Cooper, M. L. (1994). Motivations for alcohol use among adolescents: Development and validation of a four-factor model. Psychol Assess, 6(2), 117.

Davis, C. (2013). Compulsive overeating as an addictive behavior: overlap between food addiction and binge eating disorder. Current Obesity Reports, 2(2), 171-178.

Davis, C., Curtis, C., Levitan, R. D., Carter, J. C., Kaplan, A. S., \& Kennedy, J. L. (2011). Evidence that 'food addiction' is a valid phenotype of obesity. Appetite, 57(3), 711-717. doi: 10.1016/j.appet.2011.08.017

Del Boca, F. K., \& Darkes, J. (2003). The validity of self-reports of alcohol consumption: state of the science and challenges for research. Addiction, 98 Suppl 2, 1-12.

Dowling, G. J., Weiss, S. R., \& Condon, T. P. (2008). Drugs of abuse and the aging brain. Neuropsychopharmacology, 33(2), 209-218. doi: 10.1038/sj.npp.1301412

This article is protected by copyright. All rights reserved. 
Eichen, D. M., Lent, M. R., Goldbacher, E., \& Foster, G. D. (2013). Exploration of "food addiction" in overweight and obese treatment-seeking adults. Appetite, 67, 22-24. doi: 10.1016/j.appet.2013.03.008

Fernandez-Alvira, J. M., Bammann, K., Pala, V., Krogh, V., Barba, G., Eiben, G., . . Moreno, L. A. (2014). Country-specific dietary patterns and associations with socioeconomic status in European children: the IDEFICS study. Eur J Clin Nutr, 68(7), 811-821. doi: 10.1038/ejcn.2014.78

Fitzgibbon, M. L., Spring, B., Avellone, M. E., Blackman, L. R., Pingitore, R., \& Stolley, M. R. (1998). Correlates of binge eating in Hispanic, black, and white women. Int J Eat Disord, 24(1), 43-52.

Flint, A. J., Gearhardt, A. N., Corbin, W. R., Brownell, K. D., Field, A. E., \& Rimm, E. B. (2014). Food-addiction scale measurement in 2 cohorts of middle-aged and older women. Am J Clin Nutr, 99(3), 578-586. doi: 10.3945/ajcn.113.068965

Fryar, C. D., Carroll, M. D., \& Ogden, C. L. (2012). Prevalence of overweight, obesity, and extreme obesity among adults: United States, trends 1960-1962 through 20092010. Hyattsville, MD: National Center for Health Statistics.

Gearhardt, A. N., Boswell, R. G., \& White, M. A. (2014). The association of "food addiction" with disordered eating and body mass index. Eat Behav, 15(3), 427-433. doi: 10.1016/j.eatbeh.2014.05.001

Gearhardt, A. N., Corbin, W. R., \& Brownell, K. D. (2009). Preliminary validation of the Yale Food Addiction Scale. Appetite, 52(2), 430-436. doi: 10.1016/j.appet.2008.12.003

Gearhardt, A. N., Corbin, W. R., \& Brownell, K. D. (2016). Development of the Yale Food Addiction Scale Version 2.0. Psychol Addict Behav, 30(1), 113-121. doi: $10.1037 / \mathrm{adb} 0000136$

Gearhardt, A. N., Davis, C., Kuschner, R., \& Brownell, K. D. (2011). The addiction potential of hyperpalatable foods. Curr Drug Abuse Rev, 4(3), 140-145.

Gearhardt, A. N., Grilo, C. M., DiLeone, R. J., Brownell, K. D., \& Potenza, M. N. (2011). Can food be addictive? Public health and policy implications. Addiction, 106(7), 1208-1212. doi: 10.1111/j.1360-0443.2010.03301.x

Gearhardt, A. N., Yokum, S., Orr, P. T., Stice, E., Corbin, W. R., \& Brownell, K. D. (2011). Neural correlates of food addiction. Arch Gen Psychiatry, 68(8), 808-816. doi: 10.1001/archgenpsychiatry.2011.32

Giros, B., Jaber, M., Jones, S. R., Wightman, R. M., \& Caron, M. G. (1996). Hyperlocomotion and indifference to cocaine and amphetamine in mice lacking the dopamine transporter. Nature, 379(6566), 606-612. doi: 10.1038/379606a0

Granero, R., Hilker, I., Aguera, Z., Jimenez-Murcia, S., Sauchelli, S., Islam, M. A., .. FernandezAranda, F. (2014). Food addiction in a Spanish sample of eating disorders: DSM-5 diagnostic subtype differentiation and validation data. Eur Eat Disord Rev, 22(6), 389-396. doi: 10.1002/erv.2311 
Grant, B. F., Goldstein, R. B., Saha, T. D., Chou, S. P., Jung, J., Zhang, H., . . Hasin, D. S. (2015). Epidemiology of DSM-5 Alcohol Use Disorder: Results From the National Epidemiologic Survey on Alcohol and Related Conditions III. JAMA Psychiatry, 72(8), 757-766. doi: 10.1001/jamapsychiatry.2015.0584

Hauck, C., Weiss, A., Schulte, E. M., Meule, A., \& Ellrott, T. (2017). Prevalence of 'Food Addiction' as Measured with the Yale Food Addiction Scale 2.0 in a Representative German Sample and Its Association with Sex, Age and Weight Categories. Obes Facts, 10(1), 12-24. doi: 10.1159/000456013

Hebebrand, J., Albayrak, O., Adan, R., Antel, J., Dieguez, C., de Jong, J., . . . Dickson, S. L. (2014). "Eating addiction", rather than "food addiction", better captures addictive-like eating behavior. Neurosci Biobehav Rev, 47, 295-306. doi: 10.1016/j.neubiorev.2014.08.016

Hilker, I., Sanchez, I., Steward, T., Jimenez-Murcia, S., Granero, R., Gearhardt, A. N., .. . Fernandez-Aranda, F. (2016). Food Addiction in Bulimia Nervosa: Clinical Correlates and Association with Response to a Brief Psychoeducational Intervention. Eur Eat Disord Rev, 24(6), 482-488. doi: 10.1002/erv.2473

Humensky, J. L. (2010). Are adolescents with high socioeconomic status more likely to engage in alcohol and illicit drug use in early adulthood? Subst Abuse Treat Prev Policy, 5, 19. doi: 10.1186/1747-597X-5-19

Inglis, V., Ball, K., \& Crawford, D. (2005). Why do women of low socioeconomic status have poorer dietary behaviours than women of higher socioeconomic status? A qualitative exploration. Appetite, 45(3), 334-343. doi: 10.1016/j.appet.2005.05.003

Jeffery, R. W., Baxter, J., McGuire, M., \& Linde, J. (2006). Are fast food restaurants an environmental risk factor for obesity? Int J Behav Nutr Phys Act, 3, 2. doi: 10.1186/1479-5868-3-2

Johnson, P. M., \& Kenny, P. J. (2010). Dopamine D2 receptors in addiction-like reward dysfunction and compulsive eating in obese rats. Nature neuroscience, 13(5), 635641.

Joyner, M. A., Schulte, E. M., Wilt, A. R., \& Gearhardt, A. N. (2015). Addictive-like eating mediates the association between eating motivations and elevated body mass index. Translational Issues in Psychological Science, 1(3), 217.

Kessler, R. C., Berglund, P., Demler, O., Jin, R., Merikangas, K. R., \& Walters, E. E. (2005). Lifetime prevalence and age-of-onset distributions of DSM-IV disorders in the National Comorbidity Survey Replication. Arch Gen Psychiatry, 62(6), 593-602. doi: 10.1001/archpsyc.62.6.593

Konttinen, H., Sarlio-Lahteenkorva, S., Silventoinen, K., Mannisto, S., \& Haukkala, A. (2013). Socio-economic disparities in the consumption of vegetables, fruit and energy-dense foods: the role of motive priorities. Public Health Nutr, 16(5), 873-882. doi: $10.1017 /$ S1368980012003540

This article is protected by copyright. All rights reserved. 
FOOD ADDICTION IN THE UNITED STATES

Maddock, J. (2004). The relationship between obesity and the prevalence of fast food restaurants: state-level analysis. American journal of health promotion, 19(2), 137143.

Malika, N. M., Hayman, L. W., Jr., Miller, A. L., Lee, H. J., \& Lumeng, J. C. (2015). Low-income women's conceptualizations of food craving and food addiction. Eat Behav, 18, 2529. doi: 10.1016/j.eatbeh.2015.03.005

Mensink, G. B., Schienkiewitz, A., Haftenberger, M., Lampert, T., Ziese, T., \& Scheidt-Nave, C. (2013). [Overweight and obesity in Germany: results of the German Health Interview and Examination Survey for Adults (DEGS1)]. Bundesgesundheitsblatt Gesundheitsforschung Gesundheitsschutz, 56(5-6), 786-794. doi: 10.1007/s00103012-1656-3

Meule, A., \& Gearhardt, A. N. (2014). Five years of the Yale Food Addiction Scale: Taking stock and moving forward. Current Addiction Reports, 1(3), 193-205.

Ogden, C. L., Carroll, M. D., Kit, B. K., \& Flegal, K. M. (2014). Prevalence of childhood and adult obesity in the United States, 2011-2012. JAMA, 311(8), 806-814. doi: 10.1001/jama.2014.732

Oswald, K. D., Murdaugh, D. L., King, V. L., \& Boggiano, M. M. (2011). Motivation for palatable food despite consequences in an animal model of binge eating. International journal of eating disorders, 44(3), 203-211.

Paeratakul, S., White, M. A., Williamson, D. A., Ryan, D. H., \& Bray, G. A. (2002). Sex, race/ethnicity, socioeconomic status, and BMI in relation to self-perception of overweight. Obes Res, 10(5), 345-350. doi: 10.1038/oby.2002.48

Pedram, P., Wadden, D., Amini, P., Gulliver, W., Randell, E., Cahill, F., .. . Sun, G. (2013). Food addiction: its prevalence and significant association with obesity in the general population. PloS one, 8(9), e74832. doi: 10.1371/journal.pone.0074832

Pursey, K. M., Stanwell, P., Gearhardt, A. N., Collins, C. E., \& Burrows, T. L. (2014). The prevalence of food addiction as assessed by the Yale Food Addiction Scale: a systematic review. Nutrients, 6(10), 4552-4590. doi: 10.3390/nu6104552

Richardson, J. T. E. (2011). Eta squared and partial eta squared as measures of effect size in educational research. Educational Research Review, 6(2), 135-147.

Robinson, M. J., Burghardt, P. R., Patterson, C. M., Nobile, C. W., Akil, H., Watson, S. J., . . . Ferrario, C. R. (2015). Individual Differences in Cue-Induced Motivation and Striatal Systems in Rats Susceptible to Diet-Induced Obesity. Neuropsychopharmacology, 40(9), 2113-2123. doi: 10.1038/npp.2015.71

Robinson, T. N., Killen, J. D., Litt, I. F., Hammer, L. D., Wilson, D. M., Haydel, K. F., ... Taylor, C. B. (1996). Ethnicity and body dissatisfaction: are Hispanic and Asian girls at increased risk for eating disorders? J Adolesc Health, 19(6), 384-393.

Ruddock, H. K., Christiansen, P., Halford, J. C. G., \& Hardman, C. A. (2017). The development and validation of the Addiction-like Eating Behaviour Scale. Int J Obes (Lond). doi: 10.1038/ijo.2017.158

This article is protected by copyright. All rights reserved. 
Schulte, E. M., \& Gearhardt, A. N. (2017). Development of the Modified Yale Food Addiction Scale Version 2.0. Eur Eat Disord Rev. doi: 10.1002/erv.2515

Singh, G. K., Kogan, M. D., Van Dyck, P. C., \& Siahpush, M. (2008). Racial/ethnic, socioeconomic, and behavioral determinants of childhood and adolescent obesity in the United States: analyzing independent and joint associations. Ann Epidemiol, 18(9), 682-695. doi: 10.1016/j.annepidem.2008.05.001

Smith, D. G., \& Robbins, T. W. (2013). The neurobiological underpinnings of obesity and binge eating: a rationale for adopting the food addiction model. Biol Psychiatry, 73(9), 804-810. doi: 10.1016/j.biopsych.2012.08.026

Smith, J. E., \& Krejci, J. (1991). Minorities join the majority: Eating disturbances among Hispanic and Native American youth. International journal of eating disorders, 10(2), 179-186.

Sobal, J., \& Stunkard, A. J. (1989). Socioeconomic status and obesity: a review of the literature. Psychol Bull, 105(2), 260-275.

Volkow, N. D., \& Wise, R. A. (2005). How can drug addiction help us understand obesity? Nat Neurosci, 8(5), 555-560. doi: 10.1038/nn1452

Wardle, J., Robb, K. A., Johnson, F., Griffith, J., Brunner, E., Power, C., \& Tovee, M. (2004). Socioeconomic variation in attitudes to eating and weight in female adolescents. Health Psychol, 23(3), 275-282. doi: 10.1037/0278-6133.23.3.275

Wardle, J., Waller, J., \& Jarvis, M. J. (2002). Sex differences in the association of socioeconomic status with obesity. Am J Public Health, 92(8), 1299-1304.

Wohlfarth, T., \& van den Brink, W. (1998). Social class and substance use disorders: the value of social class as distinct from socioeconomic status. Soc Sci Med, 47(1), 51-58.

Woodside, D. B., \& Garfinkel, P. E. (1992). Age of onset in eating disorders. International journal of eating disorders, 12(1), 31-36.

Ziauddeen, H., \& Fletcher, P. C. (2013). Is food addiction a valid and useful concept? Obes Rev, 14(1), 19-28. doi: 10.1111/j.1467-789X.2012.01046.x

This article is protected by copyright. All rights reserved. 
FOOD ADDICTION IN THE UNITED STATES

Table 1. Sample Demographic Characteristics Versus United States Census Data

\begin{tabular}{|c|c|c|c|}
\hline & Current Sample $\mathrm{n}=986$ & Census Data (2010) & $\begin{array}{l}\text { Chi-squared } \\
p \text {-value }\end{array}$ \\
\hline Age & $\begin{array}{l}<18: 0 \% \text { (due to consent) } \\
\text { 18-24: } 10.0 \% \\
25-44: 35.7 \% \\
45-64: 33.4 \% \\
65+: 14.8 \%\end{array}$ & $\begin{array}{l}<18: 24.0 \% \\
\text { 18-24: } 9.9 \% \\
\text { 25-44: } 26.6 \% \\
45-64: 26.4 \% \\
65+: 13.0 \%\end{array}$ & $\begin{array}{l}.01 * * \\
1.00 \\
.17 \\
.28 \\
.10\end{array}$ \\
\hline Gender & $\begin{array}{l}\text { Male: } 48.8 \% \\
\text { Female: } 51.2 \%\end{array}$ & $\begin{array}{l}\text { Male: } 49.2 \% \\
\text { Female: } 50.8 \%\end{array}$ & $\begin{array}{l}1.00 \\
1.00\end{array}$ \\
\hline Race & $\begin{array}{l}\text { White: } 68.4 \% \\
\text { Black: } 12.7 \% \\
\text { Hispanic: } 12.6 \% \\
\text { Asian: } 3.2 \% \\
\text { Other } 3.1 \% \\
\end{array}$ & $\begin{array}{l}\text { White: } 63.7 \% \\
\text { Black: } 12.6 \% \\
\text { Hispanic: } 16.3 \% \\
\text { Asian: } 4.8 \%\end{array}$ & $\begin{array}{l}.55 \\
1.00 \\
.55 \\
.47 \\
\mathrm{n} / \mathrm{a}\end{array}$ \\
\hline Income & $\begin{array}{l}<\$ 25,000: 18.6 \% \\
\$ 25,000-\$ 49,999: 23.1 \% \\
\$ 50,000-\$ 74,999: 19.8 \% \\
\$ 75,000-\$ 99,999: 13.1 \% \\
>\$ 100,000: 25.5 \%\end{array}$ & $\begin{array}{l}<\$ 25,000: 25.8 \% \\
\$ 25,000-\$ 49,999: 24.7 \% \\
\$ 50,000-\$ 74,999: 17.7 \% \\
\$ 75,000-\$ 99,999: 11.4 \% \\
>\$ 100,000: 20.4 \%\end{array}$ & $\begin{array}{l}.24 \\
.87 \\
.72 \\
.66 \\
.31\end{array}$ \\
\hline $\begin{array}{l}\text { Geographic } \\
\text { Region }\end{array}$ & $\begin{array}{l}\text { Northeast: } 17.0 \% \\
\text { Midwest: } 22.0 \% \\
\text { West: } 23.3 \% \\
\text { South: } 37.6 \%\end{array}$ & $\begin{array}{l}\text { Northeast: } 17.9 \% \\
\text { Midwest: } 21.7 \% \\
\text { West: } 23.3 \% \\
\text { South: } 37.1 \%\end{array}$ & $\begin{array}{l}.85 \\
1.00 \\
1.00 \\
1.00\end{array}$ \\
\hline
\end{tabular}

Note: $* * \mathrm{p}<.01$

This article is protected by copyright. All rights reserved. 
FOOD ADDICTION IN THE UNITED STATES

Table 2. Prevalence of Food Addiction in the Current Sample

\begin{tabular}{|c|c|c|}
\hline & $\begin{array}{c}\text { mYFAS Symptom Score } \\
\text { M, SD }\end{array}$ & $\begin{array}{c}\text { mYFAS Diagnostic Score } \\
\text { Prevalence }\end{array}$ \\
\hline \multicolumn{3}{|l|}{ Age* $^{*}$} \\
\hline $18-24(\mathrm{n}=99)$ & $2.25,3.28$ & $18.18 \%$ \\
\hline $25-34(n=235)$ & $2.77,3.83$ & $22.55 \%$ \\
\hline $35-44(n=177)$ & $2.88,4.00$ & $26.55 \%$ \\
\hline $45-54(n=142)$ & $1.22,2.41$ & $9.86 \%$ \\
\hline $55-65(n=187)$ & $0.84,2.00$ & $6.42 \%$ \\
\hline $65+(n=146)$ & $0.51,1.24$ & $2.74 \%$ \\
\hline \multicolumn{3}{|l|}{ Gender } \\
\hline Male $(n=481)$ & $1.94,3.40$ & $15.80 \%$ \\
\hline Female $(n=505)$ & $1.69,2.96$ & $14.26 \%$ \\
\hline \multicolumn{3}{|l|}{ Weight Class* } \\
\hline Underweight $(\mathrm{n}=46)$ & $4.96,4.95$ & $45.65 \%$ \\
\hline Normal weight $(n=370)$ & $1.66,3.21$ & $12.16 \%$ \\
\hline Overweight $(n=300)$ & $1.23,2.66$ & $10.00 \%$ \\
\hline Obese $(n=270)$ & $2.13,2.97$ & $19.26 \%$ \\
\hline \multicolumn{3}{|l|}{ Race* } \\
\hline White $(\mathrm{n}=674)$ & $1.45,2.90$ & $11.72 \%$ \\
\hline African-American $(n=125)$ & $1.68,2.76$ & $16.80 \%$ \\
\hline Hispanic $(n=124)$ & $3.96,4.20$ & $32.26 \%$ \\
\hline Asian $(n=32)$ & $2.41,3.52$ & $15.63 \%$ \\
\hline Other $(n=31)$ & $1.06,2.29$ & $9.68 \%$ \\
\hline \multicolumn{3}{|l|}{ Income* } \\
\hline$<\$ 25,000(n=183)$ & $1.40,2.37$ & $10.38 \%$ \\
\hline$\$ 25,000-\$ 49,999(n=228)$ & $1.65,2.83$ & $14.47 \%$ \\
\hline$\$ 50,000-\$ 74,999(n=195)$ & $1.22,2.51$ & $9.74 \%$ \\
\hline$\$ 75,000-\$ 99,999(n=129)$ & $3.09,4.24$ & $24.81 \%$ \\
\hline$>\$ 100,000(n=251)$ & $2.06,3.63$ & $17.93 \%$ \\
\hline
\end{tabular}

Note: Significant differences $(p<.01)$ in YFAS scores for each demographic characteristic are indicated by $*$.

This article is protected by copyright. All rights reserved. 
Figure 1. Age and Prevalence of mYFAS 2.0 Food Addiction and Obesity

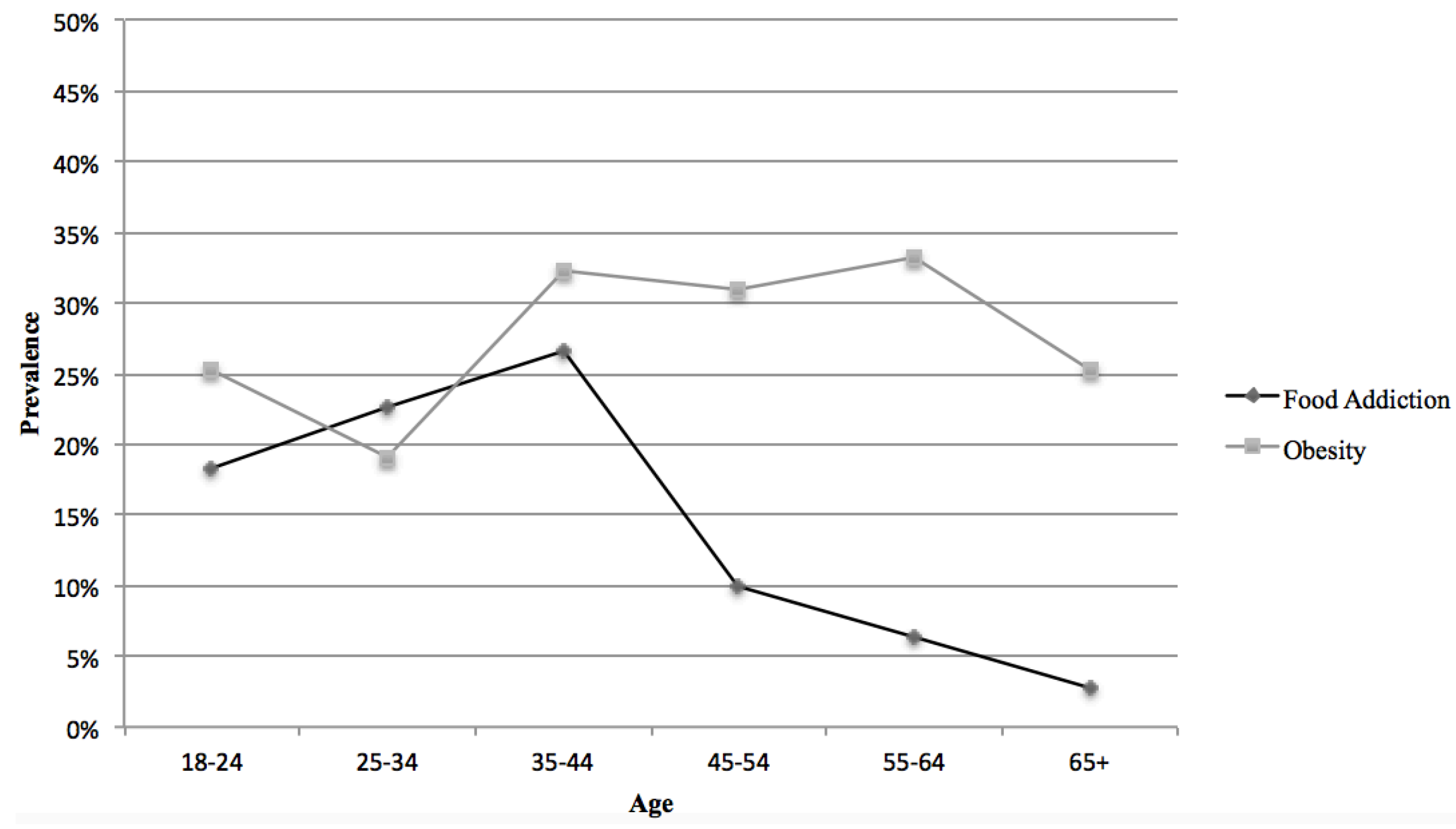

This article is protected by copyright. All rights reserved. 
Figure 2. Food Addiction Prevalence by Weight Class

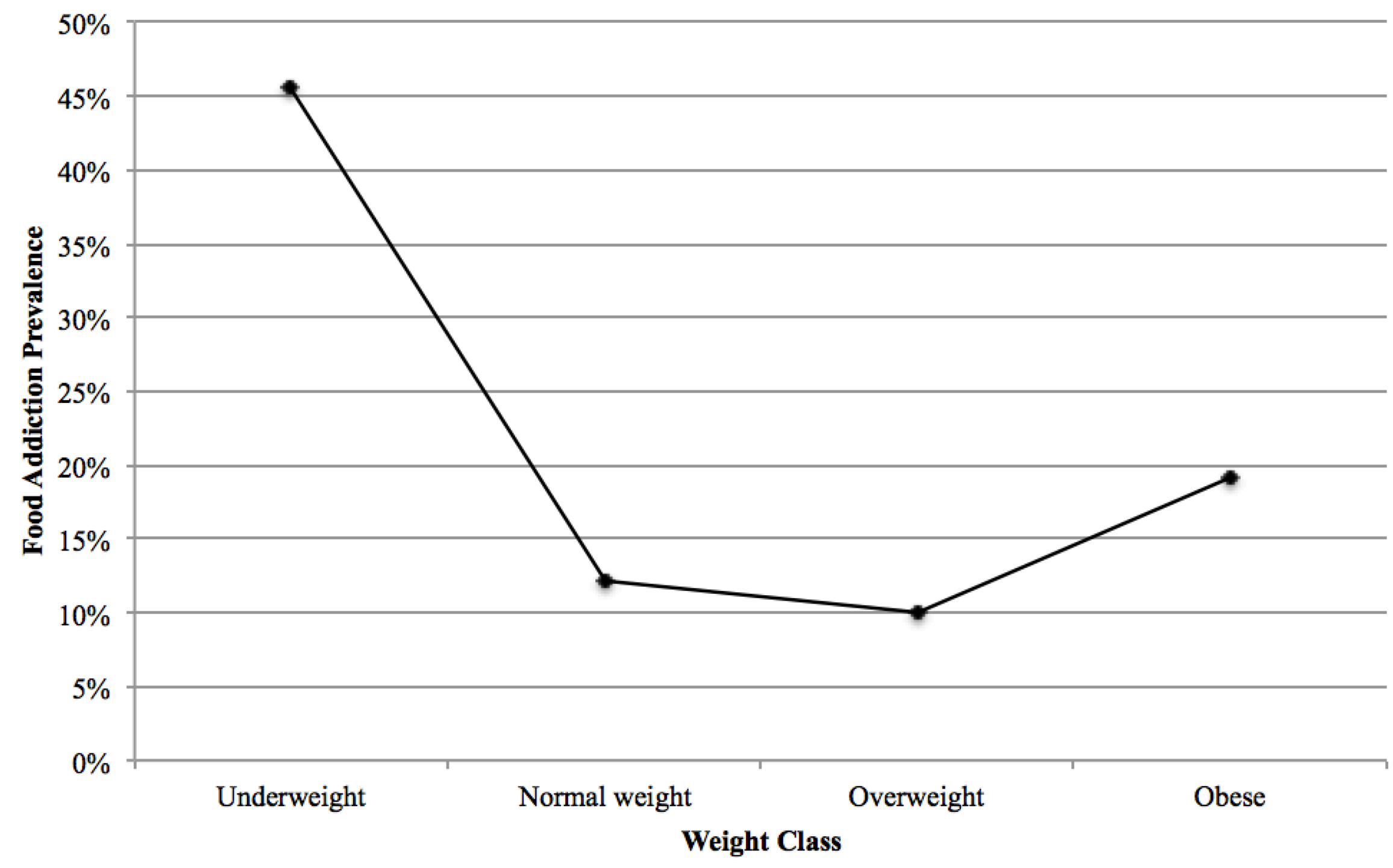

This article is protected by copyright. All rights reserved. 
Figure 1. Age and Prevalence of mYFAS 2.0 Food Addiction and Obesity

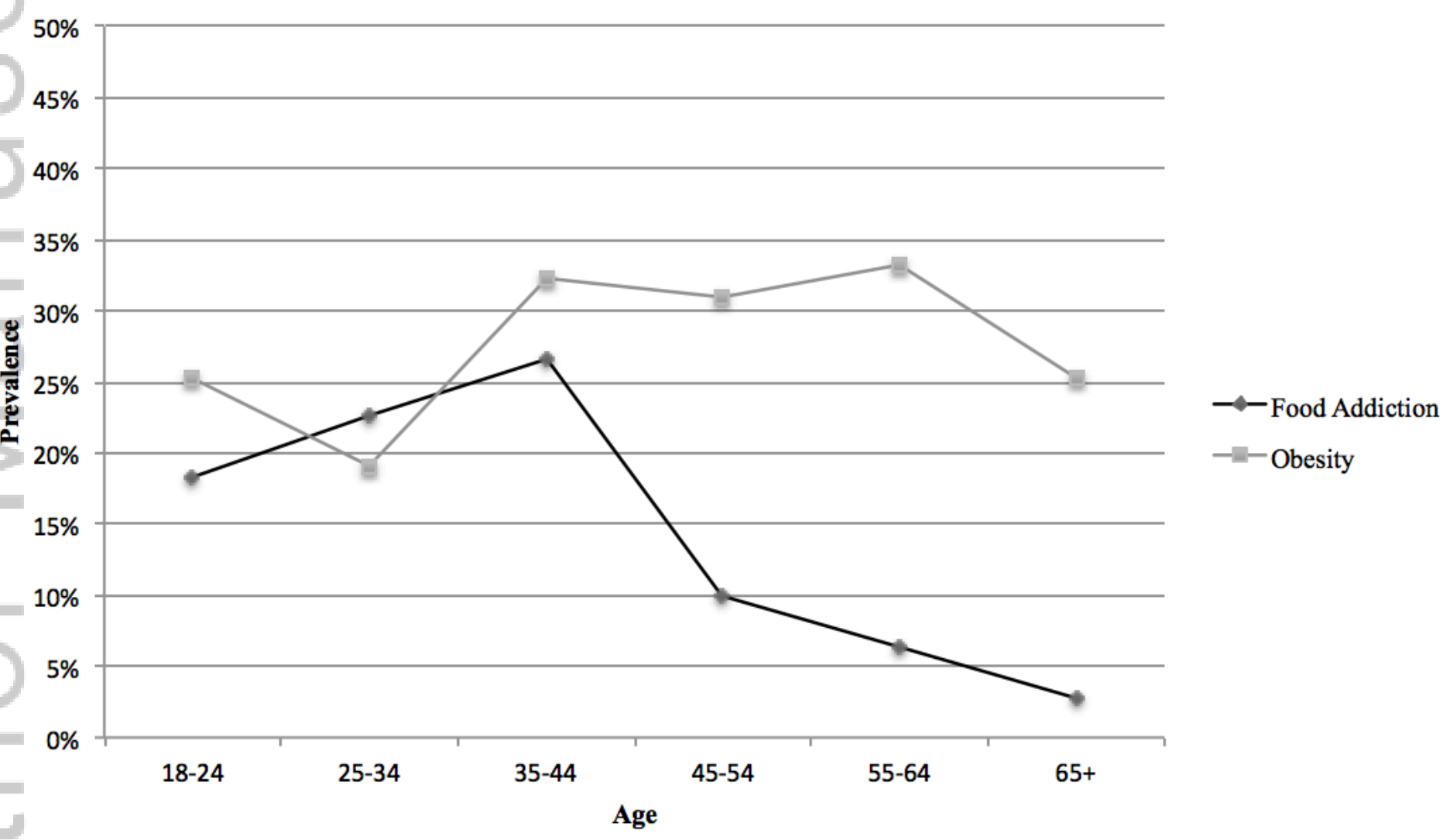

ERV_2575_F1.tiff

This article is protected by copyright. All rights reserved. 
Figure 2. Food Addiction Prevalence by Weight Class

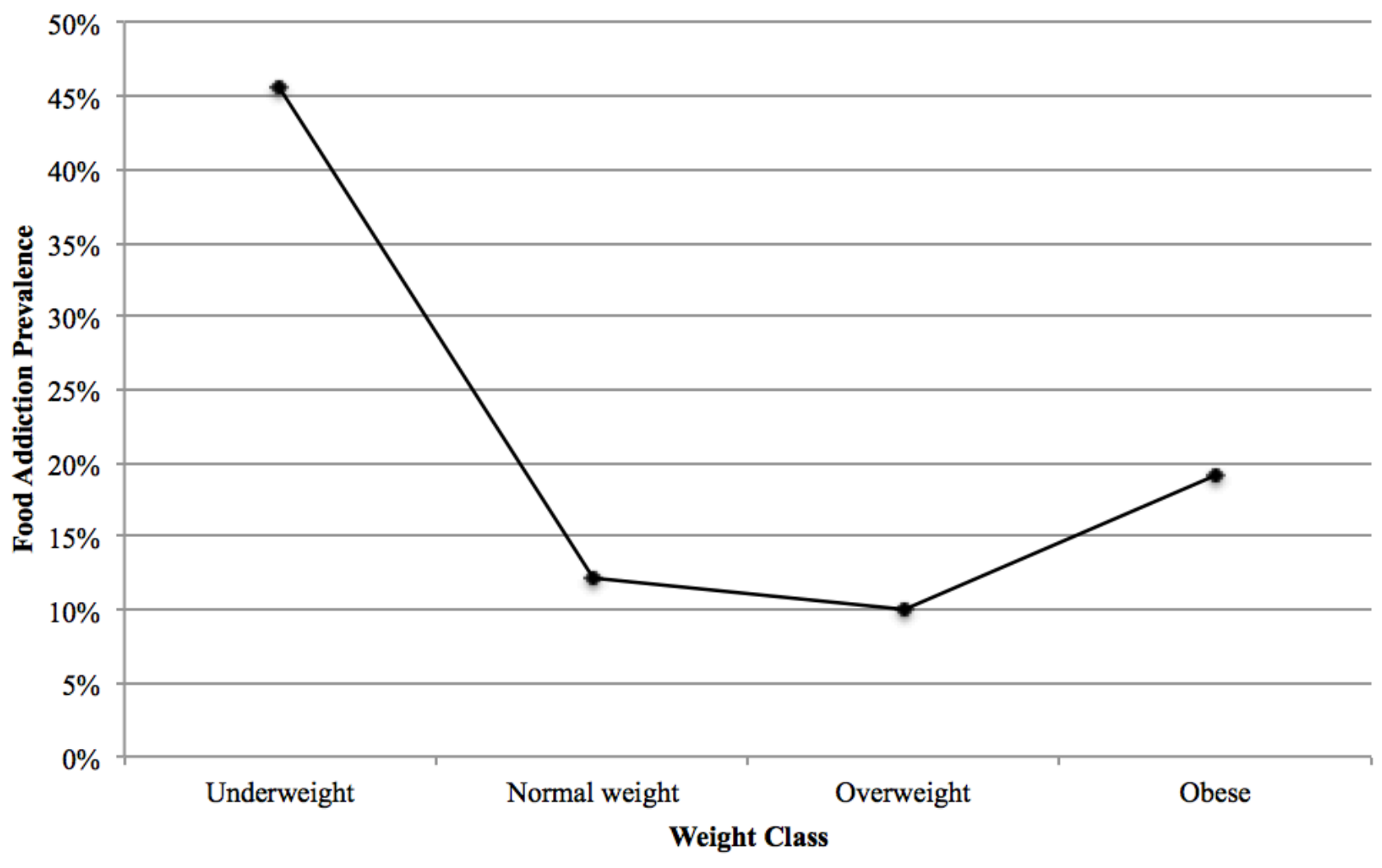

ERV_2575_F2.tiff

This article is protected by copyright. All rights reserved. 